\title{
APROXIMACIÓN A UN MODELO DE GOBERNANZA EN UNIVERSIDADES PUBLICAS \\ DE LA PROVINCIA DE PICHINCHA DEL ECUADOR
}

\section{APPROXIMATION TO A MODEL OF GOVERNANCE IN PUBLIC UNIVERSITIES OF THE PROVINCE OF PICHINCHA OF ECUADOR}

\author{
Betzabé del Rosario Maldonado Mera \\ Universidad de las Fuerzas Armadas ESPE \\ Sangolquí - Ecuador \\ brmaldonado@espe.edu.ec
}

\author{
José Javier Buenaño Cabrera \\ Universidad de las Fuerzas Armadas ESPE \\ Sangolquí - Ecuador \\ ibuenanio@espe.edu.ec
}

\author{
Karla Viviana Benavides Espinosa \\ Universidad de las Fuerzas Armadas ESPE \\ Sangolquí - Ecuador \\ kvbenavides@espe.edu.ec
}

Fecha de recepción: 09/03/2019 - Fecha de aprobación:31/05/2019

\section{RESUMEN}

En la última década se observan cambios sustanciales en el sistema de educación superior de Ecuador, cuya dinámica ha incidido en marcadas transformaciones al interior de las universidades. Este trabajo sigue las líneas de investigación desde una perspectiva de gobernanza interna, para realizar una aproximación a los modelos imperantes en las universidades que participan en el estudio. El análisis se realiza desde un enfoque sistémico, desde donde se asocia el término gobernanza a la capacidad del gobierno para definir el quehacer de las instituciones de educación superior y a las formas de organización interna para cumplir el papel otorgado. El estudio es de tipo documental eminentemente cualitativo, basado en fuentes de información obtenidas en sitios Web oficiales de las universidades y de diversos organismos. De manera complementaria, se aplica un cuestionario a través de encuesta a asesores de las mismas instituciones, con la finalidad de ratificar o matizar las conclusiones generadas. Para el análisis se considera como principios de gobernanza, la autonomía, libertad académica, rendición de cuentas, participación y representatividad institucional. Los resultados revelan que los mecanismos de control implementados por el Estado inciden al interior de las universidades y configuran diferencias en la dimensionalidad y modelos con la que ejercen la gobernanza.

PALABRAS CLAVE: Gobernanza universitaria; Autonomía universitaria; Educación superior.

\footnotetext{
"Visión de Futuro" Año 16, Volumen No 23 N², Julio - Diciembre 2019 - Pág. 102 - 121 URL de la Revista: http://visiondefuturo.fce.unam.edu.ar/index.php/visiondefuturo/index URL del Documento: http://visiondefuturo.fce.unam.edu.ar/index.php/visiondefuturo/issue/view/16 ISSN 1668 - 8708 - Versión en Línea 


\section{ABSTRACT}

In the last decade, relevant changes have been observed in the Ecuador higher education system, whose dynamics have influenced in important transformations within the universities. This work follows the lines of research from an internal governance perspective, to make an approximation to the prevailing models in the universities that participate in the study. This work follows the lines of research from an internal government perspective, to make an approximation to the prevailing models in the universities that participate in the study. The analysis is carried out from a systemic approach, from where the term governance is associated with the capacity of the government to define the task of higher education institutions and the forms of internal organization to fulfill the role granted. The study is eminently qualitative documentary type, based on information sources obtained from official websites of universities and various higher education organizations. In a complementary manner, a questionnaire is apply through an interview with advisors from the same institutions, in order to ratify or qualify the conclusions generated. For the analysis, the principles of governance, autonomy, academic freedom, accountability, participation and institutional representation are considered. The results revealed that even though the three HEls involved in the study are public and domiciled in the same province, they differ in the manner in which these principles are exercised. This intensity determines different forms of organization and models of internal operation.

KEY WORDS: University governance; University autonomy; Higher education.

\section{INTRODUCCIÓN}

La sección primera de la Constitución de Ecuador se refiere al ámbito Educación, determina que es un servicio público, garantiza la participación activa de todos y la gratuidad de la educación superior. Resalta que la educación se rige por los principios de cogobierno, igualdad de oportunidades, calidad, pertinencia, integralidad, pensamiento universal y producción científica tecnológica global (Asamblea Constituyente, 2008).

Bajo el marco normativo que regulaba el Sistema de Educación Superior (SES) en el Ecuador antes del 2008, las Instituciones de Educación Superior (IES) ejercían una absoluta autonomía universitaria en todas sus funciones esenciales. Condición que derivó en una insuficiente calidad universitaria, que se puso en evidencia con los resultados de la primera evaluación realizada en el mismo año por el organismo competente (CONEA, 2009).

Estos resultados fueron determinantes en la definición de políticas de gobierno

\footnotetext{
"Visión de Futuro" Año 16, Volumen N²3 N², Julio - Diciembre 2019 - Pág. 102 - 121

URL de la Revista: http://visiondefuturo.fce.unam.edu.ar/index.php/visiondefuturo/index

URL del Documento: http://visiondefuturo.fce.unam.edu.ar/index.php/visiondefuturo/issue/view/16 
tendientes a mejorar el SES. Se generó un amplio marco normativo que regula el accionar de las IES e incorpora principios sobre los cuales se debe sustentar el ejercicio de autonomía universitaria responsable, la rendición de cuentas y participación en la planificación nacional.

La dinámica de transformación observada en el SES se extienden a la gobernanza interna de las IES, según Brunner \& Ganga estas "deben adaptarse a las nuevas circunstancias de sistemas masificados y organizaciones más complejas" (Brunner \& Ganga, 2016, p. 15), características que coinciden con las observadas en el sistema ecuatoriano.

En este contexto surgen las preguntas: ¿Cuáles son los principios desde los cuales se aborda la gobernanza interna en el contexto universitario? y ¿Cuáles son las prácticas observadas que configuran los modelos de gobernanza en las IES estudiadas durante el periodo 2008 - 2018?

El objetivo de esta investigación es identificar el modelo de gobernanza al que se aproxima cada una de las universidades públicas domiciliadas en la Provincia de Pichincha. Desde esta propuesta se dará lugar a varios estudios que impulsen sinergias entre los actores para establecer un modelo eficaz de gobernanza en las IES públicas.

El documento se organiza como sigue. Se expone una revisión bibliográfica de varios autores versados en el tema de estudio, para identificar diferentes modelos de gobernanza universitarios desde una perspectiva interna. Se observan principios de gobernanza como dimensiones o ámbitos de estudio, a partir de los cuales se definen variables requeridas para el levantamiento de la información. Posteriormente se expone la metodología de investigación y seguidamente los resultados del análisis documental y de las encuestas aplicadas a los asesores universitarios. Se concluye puntualizando el modelo de gobernanza imperante en cada una de las IES que participan en el estudio.

\section{DESARROLLO}

\section{Gobernanza Universitaria}

El término governance traducido al español como gobernanza, es de origen angloamericano y se difundió a principios de los noventa. Mayntz lo define como "todas las formas que asume la regulación colectiva de los asuntos sociales: desde la autorregulación civil, pasando por diversas formas de acción conjunta de actores estatales y privados, hasta el accionar de actores exclusivamente estatales" (Mayntz, 2006, p.104).

La gobernanza vista más allá de la figura del Estado se entiende como una nueva forma de gobernar, entre los distintos niveles de gobierno y de estos con las organizaciones externas con quien interactúa (Prats, 2016). Desde este enfoque, en el proceso de

\footnotetext{
“Visión de Futuro" Año 16, Volumen N²3 N², Julio - Diciembre 2019 - Pág. 102 - 121

URL de la Revista: http://visiondefuturo.fce.unam.edu.ar/index.php/visiondefuturo/index

URL del Documento: http://visiondefuturo.fce.unam.edu.ar/index.php/visiondefuturo/issue/view/16

ISSN 1668 - 8708 - Versión en Línea

E-mail: revistacientifica@fce.unam.edu.ar
} 
gobernanza intervienen varios actores, gobierno, organizaciones de la sociedad civil y empresas, generando un gobierno de redes de interacción entre el sector público, privado y civil (Carrasco, 2017).

En el ámbito de la educación superior, la gobernanza ha sido uno de los principales factores considerados en la agenda de modernización, debido que no solo afecta aspectos internos de la gestión universitaria, sino también se vincula al papel del Estado y de los diferentes actores externos (Endika, 2012).

Rhodes (1996) aborda la gobernanza educativa desde una visión de redes, donde es fundamental las relaciones entre los diferentes actores del sector, se conoce la política de gobierno y se establecen espacios de interacción de grupos organizados, gubernamentales, políticos, empresariales y sociales. Esta concepción tiene sus inicios en los años 1970 a 1980, en donde el gobierno del Reino Unido ejercitó un proceso consensuado de políticas estatales con actores de gobierno y no gubernamentales (Santizo Rodall, 2011).

Gayle et al, (2011) sostienen que la gobernanza se refiere a la estructura y la toma de decisiones en las universidades cuyas implicaciones afectan a agentes internos tales como, órganos de gobierno, aprobaciones presupuestarias, contrataciones, entre otros. Así como también a los organismos externos que son establecidos por organismos estatales superiores.

La concepción de gobernanza universitaria propuesta por Brower (2015) se relaciona a los procedimientos que posibilitan la interacción horizontal de diferentes actores públicos y privados. Dinámica necesaria en el ámbito de la educación superior para viabilizar los acuerdos sociales y cumplir la misión de la universidad como tal.

Alcántara (2012) coincide con estas posturas y señala que la gobernanza en el ámbito de la educación superior, constituye un conjunto de ajustes formales e informales que viabilizan la toma de decisiones y ejecución de acciones. Además, es posible analizarla desde la esfera nacional y desde la institucional. Lo que permite diferenciar entre gobernanza externa y gobernanza interna. La gobernanza externa ocupa las relaciones individuales de cada IES con los organismos que regulan el sistema educativo, mientras que la gobernanza interna, de las líneas de autoridad al interior de las IES.

Desde la perspectiva sistémica, la diversidad observada en las IES en cuanto a su tipología y objetivos incorpora un nivel de complejidad importante que dificulta disponer un modelo de gobernanza y control de calidad, más apropiados para la gestión universitaria.

Este trabajo sigue las líneas de investigación desde una perspectiva de gobernanza interna, para realizar una aproximación a los modelos imperantes en cada una de las IES que participan en el estudio. El análisis se realiza desde un enfoque sistémico, desde donde se asocia la gobernanza universitaria a la capacidad del gobierno para definir el quehacer de

\footnotetext{
"Visión de Futuro" Año 16, Volumen Nº 23 N², Julio - Diciembre 2019 - Pág. 102 - 121

URL de la Revista: http://visiondefuturo.fce.unam.edu.ar/index.php/visiondefuturo/index

URL del Documento: http://visiondefuturo.fce.unam.edu.ar/index.php/visiondefuturo/issue/view/16

ISSN 1668 - 8708 - Versión en Línea

E-mail: revistacientifica@fce.unam.edu.ar
} 
las IES (top-down). Además se observa la manera en que se organizan internamente para cumplir el papel otorgado en el ámbito educativo, centrando el análisis en la configuración de gobierno a nivel institucional (button-up).

\section{Modelos de Gobernanza Universitaria}

Desde la perspectiva de gobernanza universitaria interna se distinguen cuatro modelos a partir "de las funciones que ejercen los organismos que están en la cúspide de la estructura universitaria, y la forma en que se relacionan con aquellos que están jerárquicamente por debajo de él" (Uauy et al, 2014, pág. 10).

El modelo de gobernanza universitaria Eficientista Normativo $(A)$ corresponde a un tipo de gobierno cuya función es eminentemente ejecutiva y su conformación eficientista. El modelo contrario es Normativo Participativo (C). En cambio en el modelo Eficientista Ejecutivo (B), las funciones son eminentemente normativas y su conformación eficientista, el modelo contrario es Efectivo Participativo (D). El presente estudio de aproximación al modelo de gobernanza de las IES se basa en esta propuesta.

La propuesta considera que en las IES existen dos estructuras de gobierno, la estructura central que comprende los organismos de decisión y las estructuras locales que corresponde a diversas escalas de división de las unidades académicas. División que suele adoptar formas de facultades, departamentos, entre otros. Como es el caso de las tres universidades que intervienen en la presente investigación.

\section{Principios de la Gobernanza en el ámbito de la educación superior}

De acuerdo con Ganga et al, (2017), a partir de estudios de Leslie (1975), Barret (1963), Moran (1971), Peterson (1971), Pfnister (1970) y Richardson (1974), la gobernanza universitaria tiene que ver con grupos de interés, participación, elementos del gobierno, nivel o contexto y asuntos administrativos.

Cifuentes et al, (2016) establece como dimensiones específicas de gobernanza universitaria, autonomía universitaria, pertinencia, calidad, planeación y financiación. Castro y Gairín (2013) definen como principios de gobernanza universitaria, autonomía universitaria, libertad académica, rendición de cuentas, participación y representatividad institucional. El presente estudio toma en cuenta estos principios en la medida que son abordados en el cuerpo normativo que regula el sistema de educación superior ecuatoriano.

Autonomía universitaria: El artículo 355 de la Constitución Política de la República del Ecuador, establece que "El Estado reconocerá a las universidades y escuelas politécnicas autonomía académica, administrativa, financiera y orgánica, acorde a los objetivos del régimen de desarrollo y los principios establecidos en la Constitución..."

\footnotetext{
"Visión de Futuro" Año 16, Volumen N²3 N², Julio - Diciembre 2019 - Pág. 102 - 121

URL de la Revista: http://visiondefuturo.fce.unam.edu.ar/index.php/visiondefuturo/index

URL del Documento: http://visiondefuturo.fce.unam.edu.ar/index.php/visiondefuturo/issue/view/16

ISSN 1668 - 8708 - Versión en Línea

E-mail: revistacientifica@fce.unam.edu.ar
} 
(Asamblea Constituyente, 2008).

La LOES en su artículo 18 indica que autonomía responsable consiste en la independencia para que los profesores e investigadores ejerzan la libertad de cátedra e investigación, libertad para expedir sus estatutos, elaborar planes y programas de estudio, nombrar personal docente y discente cumpliendo la alternancia y la equidad de género, gestionar sus procesos internos, aprobar su presupuesto interno, administrar su patrimonio, administrar sus recursos y capacidad para determinar sus formas y órganos de gobierno (Asamblea Nacional, 2010) .

Rendición de cuentas: La LOES en sus artículos 25 y 27 determina que las IES deben rendir cuentas anuales sobre el cumplimiento de sus fines y uso de fondos públicos recibidos, a la Contraloría General del Estado, al SENESCYT y Consejo de Educación Superior, su observancia lo realiza el Rector (Asamblea Nacional, 2010). Se puede pensar que la libertad universitaria está vinculada a una mejor eficiencia de gestión interna, a un aseguramiento de la calidad académica e investigativa y a una mejor respuesta al sector que atiende.

La rendición de cuentas representa transparencia sobre la actuación de las instituciones, lo que permite que sus estudiantes, empresarios y demás actores se mantengan informados. De manera interna las IES también se benefician de la transparencia como un medio de retroalimentación para la toma de decisiones (Bengoetxea, 2012).

Libertad académica: Marín destaca que libertad académica, "dentro de la legalidad es la autonomía para cuestionar y poner en duda los conocimientos recibidos, plantear otros pensamientos y soportar opiniones distintas y polémicas o impopulares sin que eso signifique que pierda su cargo en la IES" (Marín V., 2011, p. 208). Sin embargo, al depender de las asignaciones presupuestarias del gobierno que exige rendir cuentas y mejorar la eficiencia, puede traer como consecuencia la mediocridad académica.

Participación y representatividad institucional: El ejercicio de la autonomía universitaria tiene su fundamento en el cogobierno, la Ley Orgánica de Educación Superior (LOES) en el artículo 45 define al cogobierno como la dirección compartida de las IES guardando los principios de calidad, alternabilidad e igualdad de oportunidades, por parte de los diferentes actores interesados, docentes, estudiantes y personal administrativo.

\section{Metodología de investigación}

La investigación es de tipo descriptiva con levantamiento de información bibliográfica obtenida de sitios Web oficiales de las IES que intervienen en el estudio y de diversas entidades estatales. Las IES consideradas son públicas domiciliadas en la Provincia de

\footnotetext{
"Visión de Futuro" Año 16, Volumen N² 23 N², Julio - Diciembre 2019 - Pág. 102 - 121

URL de la Revista: http://visiondefuturo.fce.unam.edu.ar/index.php/visiondefuturo/index

URL del Documento: http://visiondefuturo.fce.unam.edu.ar/index.php/visiondefuturo/issue/view/16 
Pichincha, Universidad de las Fuerzas Armadas (ESPE), Universidad Central del ecuador (UCE) y Escuela Politécnica Nacional (EPN).

Siguiendo a Prats (2016) la investigación se realizó desde una perspectiva interna, se analizaron documentos oficiales de cada IES, emitidos por el Honorable Consejo Universitario y Politécnico, actas, resoluciones, informes y normativa legal aprobada por este estamento.

Para afinar el estudio se aplicó un cuestionario a través de encuesta a asesores institucionales que con alto conocimiento de la gestión universitaria y del SES aportaron objetivamente a la investigación. El cuestionario se estructuró en dos partes, una con preguntas abiertas para identificar el criterio de los informantes sobre el concepto y principios de gobernanza. La segunda parte con preguntas cerradas conducentes a cuantificar los indicadores relacionados al ejercicio de gobernanza al interior de cada IES.

A partir de esta información se realiza un análisis para aproximar el modelo de gobernanza interna de las IES a uno de los cuatro modelos de gobernanza universitaria propuestos por Uauy y otros autores (2014).

En la Tabla № 1 se describen las dimensiones de gobernanza y variables consideradas en el estudio, las mismas que guardan relación con los indicadores de los modelos de gobernanza de las IES y del SES. Las dimensiones se corresponden a los principios de gobernanza definidos por Castro \& Gairín (2013).

Tabla № 1. Dimensiones y Variables de Gobernanza

\begin{tabular}{|c|c|}
\hline Dimensiones & Variables \\
\hline \multirow[t]{7}{*}{ Autonomía universitaria } & Normativa Interna \\
\hline & Plan estratégico y operacional \\
\hline & Presupuesto \\
\hline & Estructura universitaria \\
\hline & Convenios interinstitucionales \\
\hline & Administración de bienes \\
\hline & Inferencia de organismos gubernamentales \\
\hline \multirow[t]{6}{*}{ Libertad Académica } & Carreras de pre y posgrado \\
\hline & Títulos honoríficos \\
\hline & Modelo pedagógico \\
\hline & Programas de carreras con otras IES \\
\hline & Extensiones o sedes \\
\hline & Contratación de docentes y discentes \\
\hline \multirow[t]{3}{*}{ Rendición de cuentas } & Información detallada y completa \\
\hline & Transparencia \\
\hline & Medios de comunicación \\
\hline
\end{tabular}

\footnotetext{
"Visión de Futuro" Año 16, Volumen N²3 N², Julio - Diciembre 2019 - Pág. 102 - 121

URL de la Revista: http://visiondefuturo.fce.unam.edu.ar/index.php/visiondefuturo/index

URL del Documento: http://visiondefuturo.fce.unam.edu.ar/index.php/visiondefuturo/issue/view/16

ISSN 1668 - 8708 - Versión en Línea

E-mail: revistacientifica@fce.unam.edu.ar
} 


\begin{tabular}{ll}
\hline Participación y representatividad & Órganos colegiados - Cogobierno \\
\cline { 2 - 2 } institucional & Conformación de gremios \\
\cline { 2 - 2 } & Discriminación etnia, genero, religión, entre otros \\
\cline { 2 - 2 } & Derechos de la comunidad universitaria
\end{tabular}

Fuente: Elaboración Propia considerando los principios de Castro \& Gairín (2013)

La verificación de cumplimiento de las variables se realiza a través de la revisión de diversos medios que se detallan en la Tabla № 2 .

Tabla № 2. Medios de verificación de las variables de la gobernanza universitaria

\begin{tabular}{|c|c|c|}
\hline $\begin{array}{l}\text { Medios de } \\
\text { verificación }\end{array}$ & Indicadores & Descripción \\
\hline \multirow[t]{3}{*}{$\begin{array}{l}\text { Verificación de } \\
\text { documentos }\end{array}$} & Disponibilidad & $\begin{array}{l}\text { IES cuenta con el documento formal al que hace referencia } \\
\text { cada una de las variables }\end{array}$ \\
\hline & $\begin{array}{l}\text { Aprobación } \\
\text { externa }\end{array}$ & $\begin{array}{l}\text { Documento reaccionado a la variable requiere aprobación } \\
\text { externa }\end{array}$ \\
\hline & Organismo & $\begin{array}{l}\text { En caso de requerir aprobación externa, organismo que lo } \\
\text { aprueba }\end{array}$ \\
\hline \multirow{3}{*}{$\begin{array}{l}\text { Verificación de } \\
\text { normativa }\end{array}$} & Estatuto & \multirow{3}{*}{$\begin{array}{l}\text { Marco legal interno considera los temas observados en las } \\
\text { variables }\end{array}$} \\
\hline & Reglamentos & \\
\hline & Instructivos & \\
\hline \multirow[t]{2}{*}{$\begin{array}{l}\text { Verificación Órgano } \\
\text { Colegiado Superior }\end{array}$} & Actas & $\begin{array}{l}\text { Evidencia que el Órgano Colegiado Superior trata asuntos } \\
\text { relacionados con las variables }\end{array}$ \\
\hline & Resoluciones & \\
\hline \multirow{2}{*}{$\begin{array}{l}\text { Verificación } \\
\text { vinculación externa }\end{array}$} & Contratos & Evidencia que la IES se vincula con actores externos \\
\hline & Convenios & \\
\hline
\end{tabular}

Fuente: Elaboración Propia

\section{Resultados}

\section{Resultados de revisión documental}

En primera instancia se analizaron las evidencias relacionadas a los principios de gobernanza universitaria. Desde la Tabla № 3 hasta la Tabla № 6 se resumen los hallazgos encontrados en ESPE, que en la gran mayoría coinciden con UCE y EPN. La diferencia más relevante es que en EPN y UCE se cuenta con organizaciones de estudiantes, docentes y trabajadores, mientras que en ESPE únicamente con asociaciones de docentes y trabajadores.

La UCE no cuenta con plan estratégico ni modelo educativo, estos se encuentran en proceso de formulación. Sus acciones se orientan a través de un plan de mejoras formulado en el 2014, que atiende estrictamente a las observaciones del CEAACES (2015) como resultado de la evaluación institucional que la ubicó en categoría $\mathrm{B}$.

El orden impuesto por el SES exigió a las IES cambios en varios ámbitos, régimen de admisión y acceso, diversidad de su oferta, modalidades de estudio, evaluación del desempeño, arquitectura curricular, mecanismos de aseguramiento de la calidad, distribución presupuestaria, entre otros. Situación que coincide con el análisis realizado por

\footnotetext{
"Visión de Futuro" Año 16, Volumen No 23 N², Julio - Diciembre 2019 - Pág. 102 - 121

URL de la Revista: http://visiondefuturo.fce.unam.edu.ar/index.php/visiondefuturo/index

URL del Documento: http://visiondefuturo.fce.unam.edu.ar/index.php/visiondefuturo/issue/view/16

ISSN 1668 - 8708 - Versión en Línea

E-mail: revistacientifica@fce.unam.edu.ar
} 
Brunner (2012) quien señala que las presiones a las que se ven sometidas las IES inciden en el cambio de la propia concepción de universidad.

Así mismo, Ganga et al, (2014) enfatizan en la nueva idea de comunidad y sus nuevas formas de vinculación con el entorno. Aquí la importancia de complementar el estudio para determinar el modelo de gobernanza imperante en el SES y su impacto en la trayectoria de transformación de las IES.

Tabla № 3. Verificación principio Autonomía, ESPE 2016

\begin{tabular}{|c|c|c|c|c|c|c|c|c|c|c|c|}
\hline \multirow[t]{2}{*}{ Autonomía Universitaria } & \multicolumn{2}{|c|}{$\begin{array}{c}\text { Dispone } \\
\text { documento }\end{array}$} & \multicolumn{2}{|c|}{$\begin{array}{l}\text { Requiere } \\
\text { aprobación } \\
\text { externa }\end{array}$} & \multirow[t]{2}{*}{ 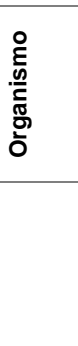 } & \multirow[t]{2}{*}{ 足 } & \multirow[t]{2}{*}{ 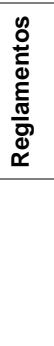 } & \multirow[t]{2}{*}{ 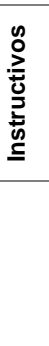 } & \multicolumn{2}{|c|}{$\begin{array}{l}\text { Del Órgano } \\
\text { Colegiado } \\
\text { Superior }\end{array}$} & \multirow[t]{2}{*}{ Observaciones } \\
\hline & SI & NO & SI & NO & & & & & $\frac{9}{\stackrel{2}{0}}$ & 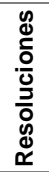 & \\
\hline \multirow[t]{2}{*}{ Normativa Interna } & $\mathrm{X}$ & & $x$ & & CES & $x$ & & & $X$ & & $\begin{array}{l}\text { El Estatuto requiere aprobación } \\
\text { interna del HCU y externa del CES. }\end{array}$ \\
\hline & & & & & & & & & & & $\begin{array}{l}\text { Tiene normativa interna que regula } \\
\text { varios ámbitos. }\end{array}$ \\
\hline \multirow[t]{2}{*}{$\begin{array}{l}\text { Plan estratégico y } \\
\text { operacional }\end{array}$} & $\mathrm{X}$ & & & $\mathrm{X}$ & & $\mathrm{X}$ & $\mathrm{X}$ & $\mathrm{X}$ & $\mathrm{X}$ & $\mathrm{X}$ & $\begin{array}{l}\text { Estatuto establece atribuciones de } \\
\text { formulación, aprobación, } \\
\text { modificación de planes. }\end{array}$ \\
\hline & & & & & & & & & & & $\begin{array}{l}\text { Reglamento Orgánico de Gestión } \\
\text { Organizacional por Procesos, } \\
\text { determina con precisión } \\
\text { atribuciones en este ámbito. } \\
\text { Instructivos con lineamientos para } \\
\text { ejecución de planes. }\end{array}$ \\
\hline Presupuesto & $\mathrm{X}$ & & $x$ & & 崫 & $\mathrm{X}$ & $\mathrm{X}$ & & $\mathrm{X}$ & $\mathrm{X}$ & $\begin{array}{l}\text { El presupuesto asignado por el } \\
\text { CES es distribuido al interior de la } \\
\text { IES, sin embargo la Secretaría } \\
\text { Nacional de Planificación y } \\
\text { Desarrollo aprueba los proyectos } \\
\text { de inversión. La LOES determina el } \\
\text { porcentaje del presupuesto que la } \\
\text { IES debe asignar a ciertos ámbitos } \\
\text { prioritarios, como becas e } \\
\text { investigación. }\end{array}$ \\
\hline Estructura universitaria & $\mathrm{X}$ & & $\mathrm{X}$ & & CES & $X$ & $\mathrm{X}$ & & $\mathrm{X}$ & & $\begin{array}{l}\text { La estructura universitaria consta } \\
\text { en el Estatuto y se profundiza en } \\
\text { sus deberes y atribuciones en los } \\
\text { reglamentos internos respectivos. }\end{array}$ \\
\hline $\begin{array}{l}\text { Convenios } \\
\text { interinstitucionales, } \\
\text { contratos }\end{array}$ & $X$ & & & $X$ & & $x$ & $\mathrm{X}$ & $\mathrm{X}$ & $X$ & $X$ & $\begin{array}{l}\text { La LOES dispone que el CES } \\
\text { apruebe convenios para programas } \\
\text { conjuntos con universidades } \\
\text { extranjeras. }\end{array}$ \\
\hline Administración bienes & $X$ & & & $\mathrm{X}$ & & $X$ & $\mathrm{X}$ & & & & \\
\hline $\begin{array}{l}\text { Injerencia organismos } \\
\text { gubernamentales }\end{array}$ & $\mathrm{X}$ & & & & & & & & & & $\begin{array}{l}\text { Organismos gubernamentales } \\
\text { remiten resoluciones a las IES que } \\
\text { son de estricto cumplimiento. }\end{array}$ \\
\hline
\end{tabular}

Fuente: Elaboración Propia

Se muestran los resultados de verificación de evidencias según los indicadores establecidos para el principio Autonomía en la Universidad de las Fuerzas Armadas ESPE.

Tabla № 4. Verificación principio Libertad Académica, ESPE 2016

\footnotetext{
"Visión de Futuro" Año 16, Volumen N²3 N², Julio - Diciembre 2019 - Pág. 102 - 121

URL de la Revista: http://visiondefuturo.fce.unam.edu.ar/index.php/visiondefuturo/index

URL del Documento: http://visiondefuturo.fce.unam.edu.ar/index.php/visiondefuturo/issue/view/16

ISSN 1668 - 8708 - Versión en Línea

E-mail: revistacientifica@fce.unam.edu.ar
} 


\begin{tabular}{|c|c|c|c|c|c|c|c|c|c|c|c|}
\hline \multirow{2}{*}{$\begin{array}{l}\text { Libertad } \\
\text { Académica }\end{array}$} & \multicolumn{2}{|c|}{$\begin{array}{c}\text { Dispone } \\
\text { documento }\end{array}$} & \multicolumn{2}{|c|}{$\begin{array}{l}\text { Requiere } \\
\text { aprobación } \\
\text { externa }\end{array}$} & \multirow{2}{*}{ 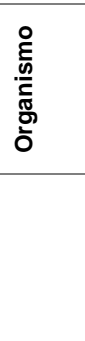 } & \multirow{2}{*}{ 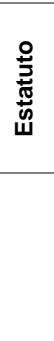 } & \multirow{2}{*}{ 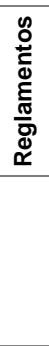 } & \multirow{2}{*}{ 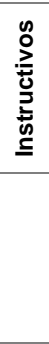 } & \multicolumn{2}{|c|}{$\begin{array}{l}\text { Del Órgano } \\
\text { Colegiado } \\
\text { Superior }\end{array}$} & \multirow[t]{2}{*}{ Observaciones } \\
\hline & SI & NO & SI & NO & & & & & 惑 & 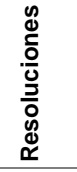 & \\
\hline $\begin{array}{l}\text { Programas } \\
\text { de grado y } \\
\text { posgrado }\end{array}$ & $x$ & & $\mathrm{X}$ & & CES & $x$ & $\mathrm{X}$ & $X$ & $x$ & $\mathrm{X}$ & $\begin{array}{l}\text { Los diseños y rediseños de programas, } \\
\text { se aprueban en el HCU y se envía al CES } \\
\text { para su aprobación definitiva. }\end{array}$ \\
\hline $\begin{array}{l}\text { Títulos } \\
\text { honoríficos }\end{array}$ & $\mathrm{X}$ & & $x$ & & CES & $\mathrm{X}$ & & & $x$ & $\mathrm{X}$ & \\
\hline $\begin{array}{l}\text { Modelo } \\
\text { educativo }\end{array}$ & $\mathrm{X}$ & & $x$ & & CES & & $\mathrm{X}$ & $\mathrm{X}$ & $x$ & $\mathrm{X}$ & $\begin{array}{l}\text { EI CES emite lineamientos del modelo } \\
\text { educativo que deben seguir las IES, } \\
\text { contiene guía de diseños y rediseños. }\end{array}$ \\
\hline $\begin{array}{l}\text { Programas } \\
\text { de carreras } \\
\text { con otras } \\
\text { IES }\end{array}$ & $x$ & & $x$ & & CES & $X$ & $\mathrm{X}$ & $\mathrm{X}$ & $x$ & $\mathrm{X}$ & $\begin{array}{l}\text { La LOES dispone que el CES apruebe } \\
\text { convenios para programas conjuntos con } \\
\text { universidades extranjeras. }\end{array}$ \\
\hline $\begin{array}{l}\text { Extensiones } \\
\text { o sedes }\end{array}$ & $\mathrm{X}$ & & $X$ & & CES & $x$ & $X$ & & $\mathrm{X}$ & $\mathrm{X}$ & \\
\hline $\begin{array}{l}\text { Contratación } \\
\text { de docentes } \\
\text { y discentes }\end{array}$ & $X$ & & & & & $\mathrm{X}$ & $\mathrm{X}$ & $X$ & $\mathrm{X}$ & $\mathrm{X}$ & \\
\hline
\end{tabular}

Fuente: Elaboración Propia

Se muestran los resultados de verificación de evidencias según los indicadores establecidos para el principio Libertad Académica en la Universidad de las Fuerzas Armadas ESPE.

Tabla № 5. Verificación principio Rendición de Cuentas, ESPE 2016

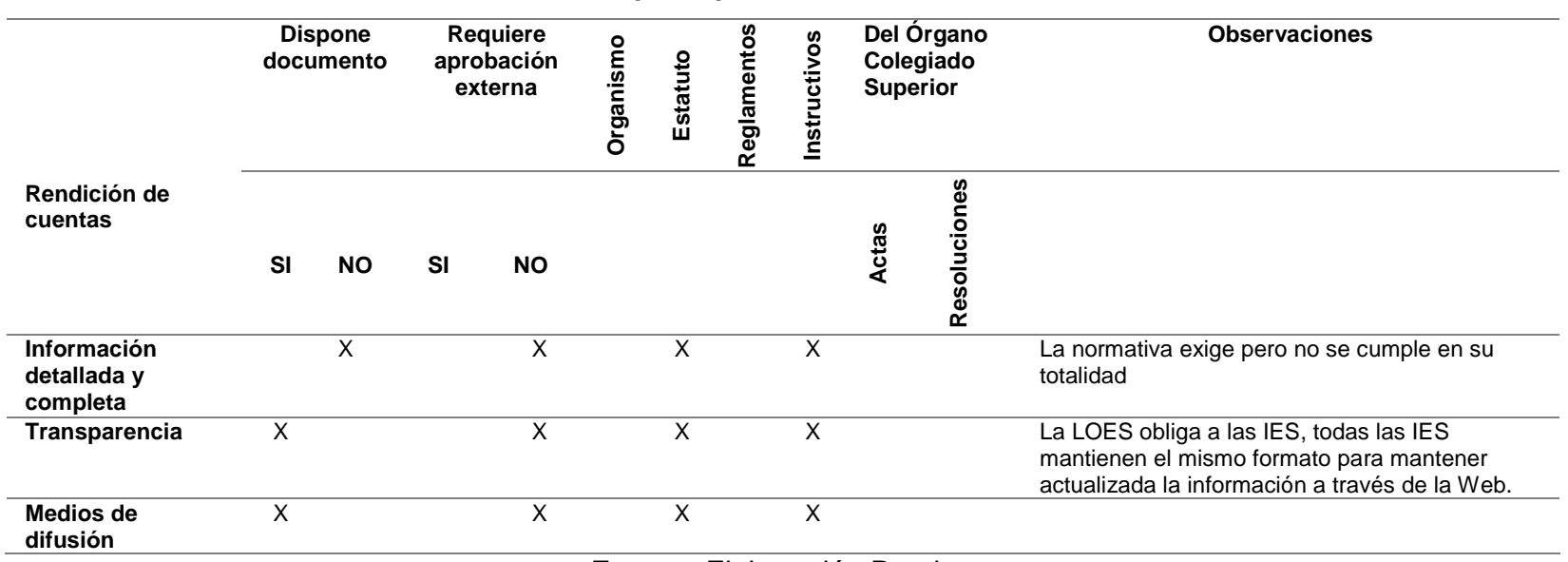

Fuente: Elaboración Propia

Se muestran los resultados de verificación de evidencias según los indicadores establecidos para el principio Rendición de Cuentas en la Universidad de las Fuerzas Armadas ESPE.

Tabla № 6. Verificación principio Libertad Académica, ESPE 2016

\footnotetext{
"Visión de Futuro" Año 16, Volumen N²3 N², Julio - Diciembre 2019 - Pág. 102 - 121

URL de la Revista: http://visiondefuturo.fce.unam.edu.ar/index.php/visiondefuturo/index

URL del Documento: http://visiondefuturo.fce.unam.edu.ar/index.php/visiondefuturo/issue/view/16

ISSN 1668 - 8708 - Versión en Línea

E-mail: revistacientifica@fce.unam.edu.ar
} 


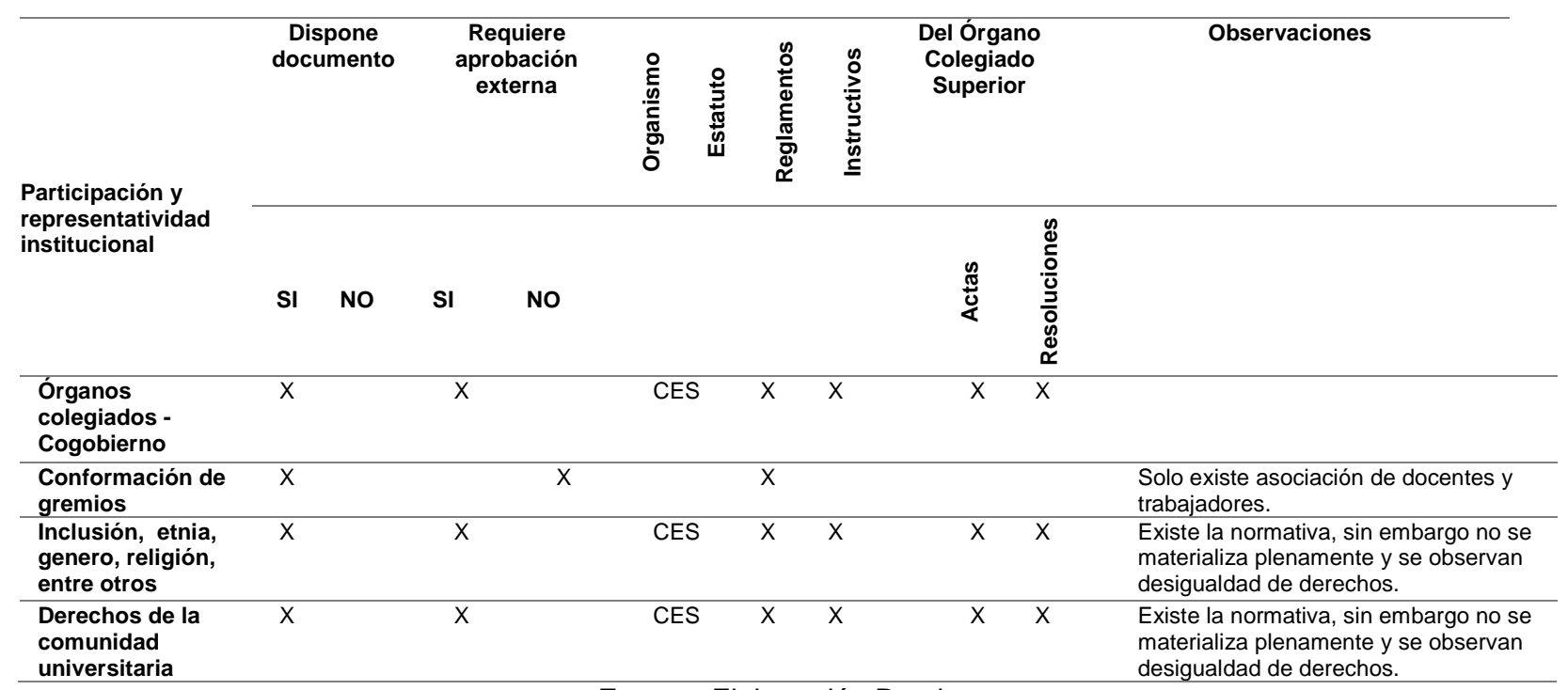

Fuente: Elaboración Propia

Se muestran los resultados de verificación de evidencias según los indicadores establecidos para el principio Participación y Representatividad en la Universidad de las Fuerzas Armadas ESPE.

Puga (2018), decano de la Facultad de Economía de la UCE, sostiene que para gobernar adecuadamente una IES pública, se deben considerar varios indicadores. Hace hincapié en el presupuesto general del Estado, como variable exógena. San Martín (2018) asesor de la ESPE, en cambio, se refiere a los sistemas de gobierno en las áreas derivadas de las funciones sustantivas de la universidad, docencia, investigación y vinculación. Señala que el área administrativa aun cuando no es parte de sus funciones sustantivas, es indispensable considerar en este sistema de gobierno. Ruiz (2018) asesor de la EPN, precisa que las dimensiones de la gobernanza universitaria, corresponden a la estructura y procesos de gobierno, autonomía y rendición de cuentas.

\section{Perspectiva dimensional y aproximación al modelo de gobernanza universitaria}

La perspectiva multidimensional de la gobernanza interna se deriva de la cuantificación de los indicadores relacionados al ejercicio de gobernanza al interior de cada IES realizada por los encuestados en la segunda parte del cuestionario.

En la Figura № 1 se observa que aun cuando las tres IES que intervienen en el estudio son públicas y domiciliadas en la misma provincia, difieren en la intensidad con la que se ejercen los principios de gobernanza. Resultado que coincide con Brunner (2011) quien relaciona la gobernanza universitaria con las distintas formas de organización y modelos de operación interna, que se configuran desde su gobierno, su modelo de gestión, y sus relaciones con entidades y actores del sistema de educación superior.

\footnotetext{
"Visión de Futuro" Año 16, Volumen N²3 N², Julio - Diciembre 2019 - Pág. 102 - 121

URL de la Revista: http://visiondefuturo.fce.unam.edu.ar/index.php/visiondefuturo/index

URL del Documento: http://visiondefuturo.fce.unam.edu.ar/index.php/visiondefuturo/issue/view/16

ISSN 1668 - 8708 - Versión en Línea

E-mail: revistacientifica@fce.unam.edu.ar
} 
En la figura se observa la diferencia de intensidad con la que se asume cada uno de los principios de gobernanza en las universidades que participan en el estudio. En autonomía y rendición de cuentas, EPN observa más intensidad que ESPE y UCE. En libertad académica coinciden con un 60\% de intensidad, EPN y UCE. En participación y representatividad institucional UCE alcanza un mayor porcentaje respecto a EPN.

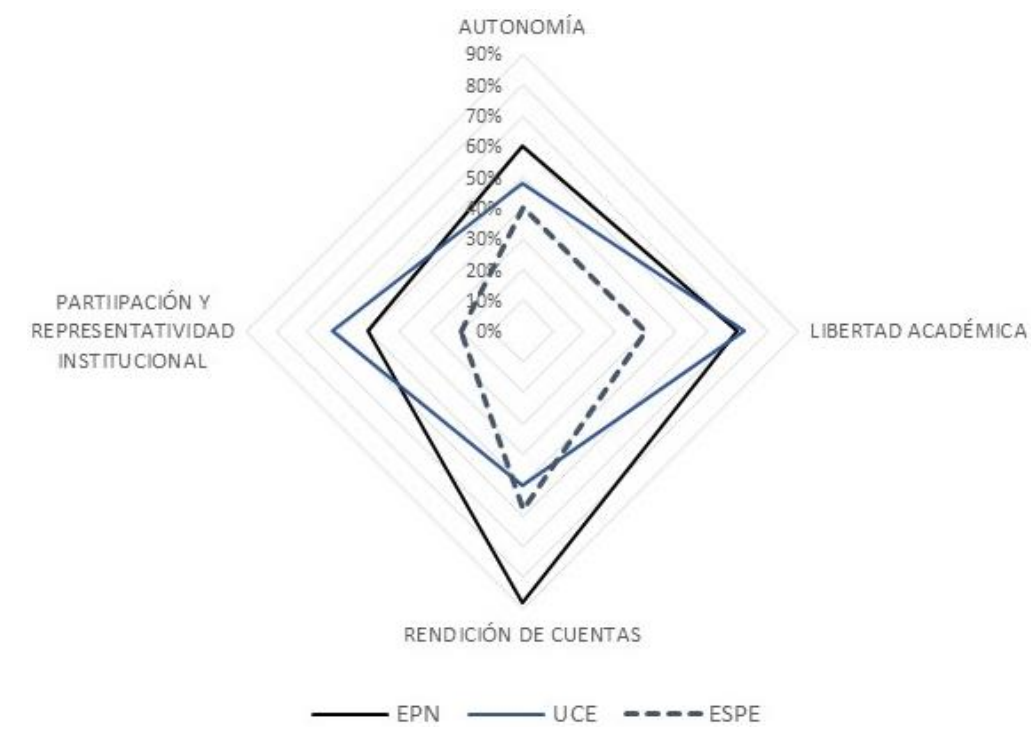

Figura № 1. Perspectiva multidimensional de la gobernanza interna universitaria

Fuente: Elaboración Propia

De este resultado se deriva la proposición 1: La intensidad con la que se ejercen los principios de gobernanza en una IES determina las distintas formas de organización y modelos de operación interna.

Este análisis conduce a profundizar las características internas de cada IES para realizar una aproximación de su modelo de gobernanza. Las formas de gobernanza difieren en cada IES según el modelo de universidad, su propia cultura organizacional, el contexto nacional, el tipo de liderazgo, entre otros aspectos.

Siguiendo a Uauy et al, (2014) se consideran las estructuras de gobierno universitario central y local, para identificar las funciones que ejercen los primeros y la forma en que se relacionan con los que están jerárquicamente por debajo, es decir con los que forman parte de las estructuras locales. El análisis se realizó en base a los documentos legales de cada IES, estatuto, reglamentos internos, manual de procesos, instructivos, entre otros y la información otorgada por los asesores. Los resultados se muestran en las Tablas № 7 y № 8 para EPN y UCE, respectivamente.

Las características observadas en las funciones y conformación de los organismos de gobierno de EPN y UCE, permiten diferenciar dos modelos de gobernanza universitario, 
Normativo Participativo en el nivel de estructura central y Eficientista Normativo en el nivel de estructura local. Aun cuando en general, predomina el modelo Normativo Participativo en las dos universidades.

Del análisis de los modelos de gobernanza internos en cada IES que se describen en las tablas anteriores, proceden las siguientes proposiciones.

Proposición 2: El modelo de gobernanza de la EPN y UCE es predominantemente normativo participativo en su nivel de estructura central, en la medida se observa una conformación de los organismos de gobierno participativo con funciones primordialmente normativas.

Proposición 3: El modelo de gobernanza de la EPN y UCE es predominantemente eficientista normativo en su nivel de estructura local, en la medida se observa una conformación de los organismos de gobierno locales eficientista con funciones primordialmente normativas.

Tabla № 7. Aproximación al modelo de gobernanza universitario de EPN

\begin{tabular}{|c|c|c|}
\hline & \multicolumn{2}{|c|}{ EPN } \\
\hline & Características & $\begin{array}{c}\text { Aproximación al modelo de gobernanza } \\
\text { universitaria }\end{array}$ \\
\hline Estructura & Consejo Politécnico es el único Organismo & Se aproxima al Modelo de Gobernanza \\
\hline \multirow[t]{3}{*}{ Central } & $\begin{array}{l}\text { Superior colegiado de cogobierno (HCP). Es } \\
\text { de carácter normativo, conformado de manera } \\
\text { pluriestamental. Sus miembros son elegidos }\end{array}$ & $\begin{array}{l}\text { Universitaria de tipo Normativo } \\
\text { Participativo. }\end{array}$ \\
\hline & $\begin{array}{l}\text { por votación universal por la comunidad } \\
\text { politécnica. } \\
\text { Fija los objetivos estratégicos y elige a las } \\
\text { autoridades ejecutivas de estructuras locales: } \\
\text { Decanos, Sub Decanos, Jefes de }\end{array}$ & $\begin{array}{l}\text { Con la diferencia que en el modelo } \\
\text { propuesto, la máxima autoridad ejecutiva es } \\
\text { designada por el organismo superior } \\
\text { colegiado de la estructura central. }\end{array}$ \\
\hline & $\begin{array}{l}\text { Departamento, etc. } \\
\text { El Rector como máxima autoridad ejecutiva es } \\
\text { quien lo preside, también es elegido por } \\
\text { votación universal, al igual que los } \\
\text { vicerrectores. }\end{array}$ & $\begin{array}{l}\text { Mientras que en la EPN el Rector es elegido } \\
\text { por votación universal por toda la comunidad } \\
\text { politécnica. }\end{array}$ \\
\hline Estructura & Se definen a las facultades como las unidades & En la EPN el Decano es elegido por el HCU. \\
\hline Local & $\begin{array}{l}\text { académicas superiores de la Politécnica. } \\
\text { Encargadas de planificar, controlar y evaluar } \\
\text { los procesos de docencia, investigación y } \\
\text { proyección social en determinada área de } \\
\text { conocimiento. Están integradas por } \\
\text { departamentos, Institutos de investigación y } \\
\text { carreras afines. }\end{array}$ & $\begin{array}{l}\text { Característica que coincide con el modelo } \\
\text { Eficientista Normativo. Presencia de } \\
\text { autoridades unipersonales designadas por el } \\
\text { organismo central. Existen organismos } \\
\text { colegiados de función normativa, con cierto } \\
\text { nivel de electividad y participación de la } \\
\text { comunidad local, presididos por la autoridad }\end{array}$ \\
\hline
\end{tabular}

\footnotetext{
“Visión de Futuro" Año 16, Volumen N²3 N², Julio - Diciembre 2019 - Pág. 102 - 121

URL de la Revista: http://visiondefuturo.fce.unam.edu.ar/index.php/visiondefuturo/index

URL del Documento: http://visiondefuturo.fce.unam.edu.ar/index.php/visiondefuturo/issue/view/16

ISSN 1668 - 8708 - Versión en Línea

E-mail: revistacientifica@fce.unam.edu.ar
} 


\section{Fuente: Elaboración Propia}

Se observa la descripción de las características observadas en la estructura central y local del gobierno universitario de EPN, frente a lo cual se aproxima el modelo de gobernanza universitaria.

Tabla № 8. Aproximación al modelo de gobernanza universitario de UCE

\begin{tabular}{|c|c|c|}
\hline & \multicolumn{2}{|r|}{ UCE } \\
\hline & Características & $\begin{array}{c}\text { Aproximación al modelo de gobernanza } \\
\text { universitaria }\end{array}$ \\
\hline $\begin{array}{l}\text { Estructura } \\
\text { Central }\end{array}$ & $\begin{array}{l}\text { Consejo Universitario es el Órgano } \\
\text { Colegiado Académico Superior. (HCU). Es } \\
\text { de carácter normativo, conformado de } \\
\text { manera pluriestamental. Sus miembros son } \\
\text { elegidos por votación universal por la } \\
\text { comunidad universitaria. } \\
\text { Fija los objetivos estratégicos. El Rector } \\
\text { como máxima autoridad ejecutiva es quien } \\
\text { lo preside, también es elegido por votación } \\
\text { universal, al igual que los vicerrectores. }\end{array}$ & $\begin{array}{l}\text { Se aproxima al Modelo de Gobernanza } \\
\text { Universitaria de tipo Normativo Participativo. Con } \\
\text { la diferencia que en el modelo propuesto, la } \\
\text { máxima autoridad ejecutiva es designada por el } \\
\text { organismo superior colegiado de la estructura } \\
\text { central. Mientras que en la UCE el Rector es } \\
\text { elegido por votación universal por toda la } \\
\text { comunidad politécnica. }\end{array}$ \\
\hline $\begin{array}{l}\text { Estructura } \\
\text { Local }\end{array}$ & $\begin{array}{l}\text { Se definen a las facultades como las } \\
\text { unidades académicas superiores de la } \\
\text { Universidad. Encargadas de planificar, } \\
\text { controlar y evaluar los procesos de } \\
\text { docencia, investigación y vinculación con la } \\
\text { sociedad en determinada área de } \\
\text { conocimiento. Están integradas por carreras } \\
\text { afines. El máximo organismo local es de } \\
\text { carácter colegiado, normativo y } \\
\text { pluriestamental. El Consejo Directivo de la } \\
\text { facultad lo preside el Decano que es } \\
\text { designado por el Rector. }\end{array}$ & $\begin{array}{l}\text { En la UCE el Decano es elegido por el Rector. } \\
\text { Característica que se aproxima al modelo } \\
\text { Eficientista Normativo. Presencia de } \\
\text { autoridades unipersonales designadas por el } \\
\text { organismo central. Existen organismos colegiados } \\
\text { de función normativa, con cierto nivel de } \\
\text { electividad y participación de la comunidad local, } \\
\text { presididos por la autoridad designada } \\
\text { centralmente. }\end{array}$ \\
\hline
\end{tabular}

Fuente: Elaboración Propia

Se observa la descripción de las características observadas en la estructura central y local del gobierno universitario de UCE, frente a lo cual se aproxima el modelo de gobernanza universitaria.

"Visión de Futuro" Año 16, Volumen No 23 N², Julio - Diciembre 2019 - Pág. 102 - 121

URL de la Revista: http://visiondefuturo.fce.unam.edu.ar/index.php/visiondefuturo/index

URL del Documento: http://visiondefuturo.fce.unam.edu.ar/index.php/visiondefuturo/issue/view/16

ISSN 1668 - 8708 - Versión en Línea

E-mail: revistacientifica@fce.unam.edu.ar 
En el caso de ESPE, el modelo de gobernanza universitaria se aproxima al Eficientista Normativo en el nivel de estructura central y Eficientista Ejecutivo en el nivel de estructura local. Los resultados se muestran en la Tabla № 9.

Del mismo modo, para ESPE proceden las siguientes proposiciones:

Proposición 4: El modelo de gobernanza de la ESPE es predominantemente eficientista normativo en su nivel de estructura central, en la medida se observa una conformación de los organismos de gobierno eficientista con funciones primordialmente normativas.

Proposición 5: El modelo de gobernanza de la ESPE es predominantemente eficientista ejecutivo en su nivel de estructura local, en la medida se observa una conformación de los organismos de gobierno locales eficientista con funciones primordialmente ejecutivas.

Tabla № 9. Aproximación al modelo de gobernanza universitario de ESPE

\begin{tabular}{|c|c|c|}
\hline & \multicolumn{2}{|r|}{ ESPE } \\
\hline & Características & $\begin{array}{c}\text { Aproximación al modelo de gobernanza } \\
\text { universitaria }\end{array}$ \\
\hline $\begin{array}{l}\text { Estructura } \\
\text { Central }\end{array}$ & $\begin{array}{l}\text { Consejo Universitario es el Órgano } \\
\text { colegiado académico superior de cogobierno } \\
\text { (HCU). Es de carácter normativo, } \\
\text { conformado de manera pluriestamental. Sus } \\
\text { miembros son elegidos por votación } \\
\text { universal por la comunidad universitaria. } \\
\text { Fija los objetivos estratégicos. El Rector } \\
\text { como máxima autoridad ejecutiva es quien lo } \\
\text { preside. Es designado por el Jefe del } \\
\text { Comando Conjunto de las Fuerzas Armadas, } \\
\text { al igual que los vicerrectores. }\end{array}$ & $\begin{array}{l}\text { Se aproxima al Modelo de Gobernanza } \\
\text { Universitaria de tipo Eficientista Normativo. Con } \\
\text { la diferencia que en este modelo, la máxima } \\
\text { autoridad ejecutiva externa es designada por el } \\
\text { organismo colegiado. Mientras que en la ESPE, el } \\
\text { Rector es designado por el Jefe del Comando } \\
\text { Conjunto de las Fuerzas Armadas, al igual que los } \\
\text { vicerrectores. Autoridad totalmente externa a la } \\
\text { estructura universitaria. }\end{array}$ \\
\hline $\begin{array}{l}\text { Estructura } \\
\text { Local }\end{array}$ & $\begin{array}{l}\text { La estructura local es matricial, constituida } \\
\text { por Departamentos, como unidades } \\
\text { académicas superiores de la Universidad. } \\
\text { Encargadas de coordinar, controlar y evaluar } \\
\text { los procesos de docencia, investigación y } \\
\text { vinculación con la sociedad en determinada } \\
\text { área de conocimiento. } \\
\text { El Consejo de Departamento es el máximo } \\
\text { organismo colegiado, integrado por el } \\
\text { director de Departamento quien lo preside y } \\
\text { cuatro docentes propuestos por el director y } \\
\text { designados por el Rector. El Director de }\end{array}$ & $\begin{array}{l}\text { En la ESPE las autoridades locales son } \\
\text { designadas por el Rector. } \\
\text { Sólo en el máximo organismo colegiado cumple la } \\
\text { característica de electividad y pluriestamental. En } \\
\text { el nivel local, los miembros de los organismos } \\
\text { colegiados son designados por el Rector. El } \\
\text { Consejo de Departamento no es de carácter } \\
\text { normativo, sino más bien ejecutivo. Es decir son } \\
\text { los encargados de la puesta en práctica de la } \\
\text { normativa, definida por el organismo central. Por lo } \\
\text { que en este nivel de la estructura, el modelo se } \\
\text { aproxima a uno Eficientista Ejecutivo. }\end{array}$ \\
\hline
\end{tabular}

\footnotetext{
"Visión de Futuro" Año 16, Volumen No 23 N², Julio - Diciembre 2019 - Pág. 102 - 121

URL de la Revista: http://visiondefuturo.fce.unam.edu.ar/index.php/visiondefuturo/index

URL del Documento: http://visiondefuturo.fce.unam.edu.ar/index.php/visiondefuturo/issue/view/16

ISSN 1668 - 8708 - Versión en Línea

E-mail: revistacientifica@fce.unam.edu.ar
} 
Departamento es designado por el Rector.

\section{Fuente: Elaboración Propia}

Se observa la descripción de las características observadas en la estructura central y local del gobierno universitario de la ESPE, frente a lo cual se aproxima el modelo de gobernanza universitaria.

La marcada diferencia entre los modelos de gobernanza de ESPE y EPN, UCE, tiene su origen en la LOES aprobada en el 2010. La misma otorga una excepción respecto al resto de IES del país, en cuanto a la designación de las autoridades. En el Artículo 55 determina que las autoridades académicas de la ESPE, se elegirán conforme a lo que determinen sus estatutos. En la Disposición Transitoria Vigésima Segunda se determina que la formulación del estatuto observará los fines y objetivos específicos, conforme a las políticas que defina el Ministerio de Defensa Nacional.

Los resultados coinciden con la valoración que realizaron los asesores de las tres instituciones educativas, a los enunciados relacionados con los ejes: funciones de los organismos de gobierno universitario y conformación de los organismos de gobierno universitario, según corresponde a la propuesta de Uauy et al, (2014).

Las características observadas no son absolutas, en el ejercicio del gobierno universitario predominan unas más que otras y configuran modelos dinámicos de gobernanza, sin embargo prevalece uno sobre los demás modelos. La Figura № 2 muestra el modelo de gobernanza universitaria al que se aproxima cada IES como resultado de la valoración de los asesores respecto a la conformación y funciones de los organismos de gobierno universitario que configuran los distintos modelos de gobernanza universitaria.

\footnotetext{
"Visión de Futuro" Año 16, Volumen Nº 23 N², Julio - Diciembre 2019 - Pág. 102 - 121

URL de la Revista: http://visiondefuturo.fce.unam.edu.ar/index.php/visiondefuturo/index

URL del Documento: http://visiondefuturo.fce.unam.edu.ar/index.php/visiondefuturo/issue/view/16

ISSN 1668 - 8708 - Versión en Línea

E-mail: revistacientifica@fce.unam.edu.ar
} 


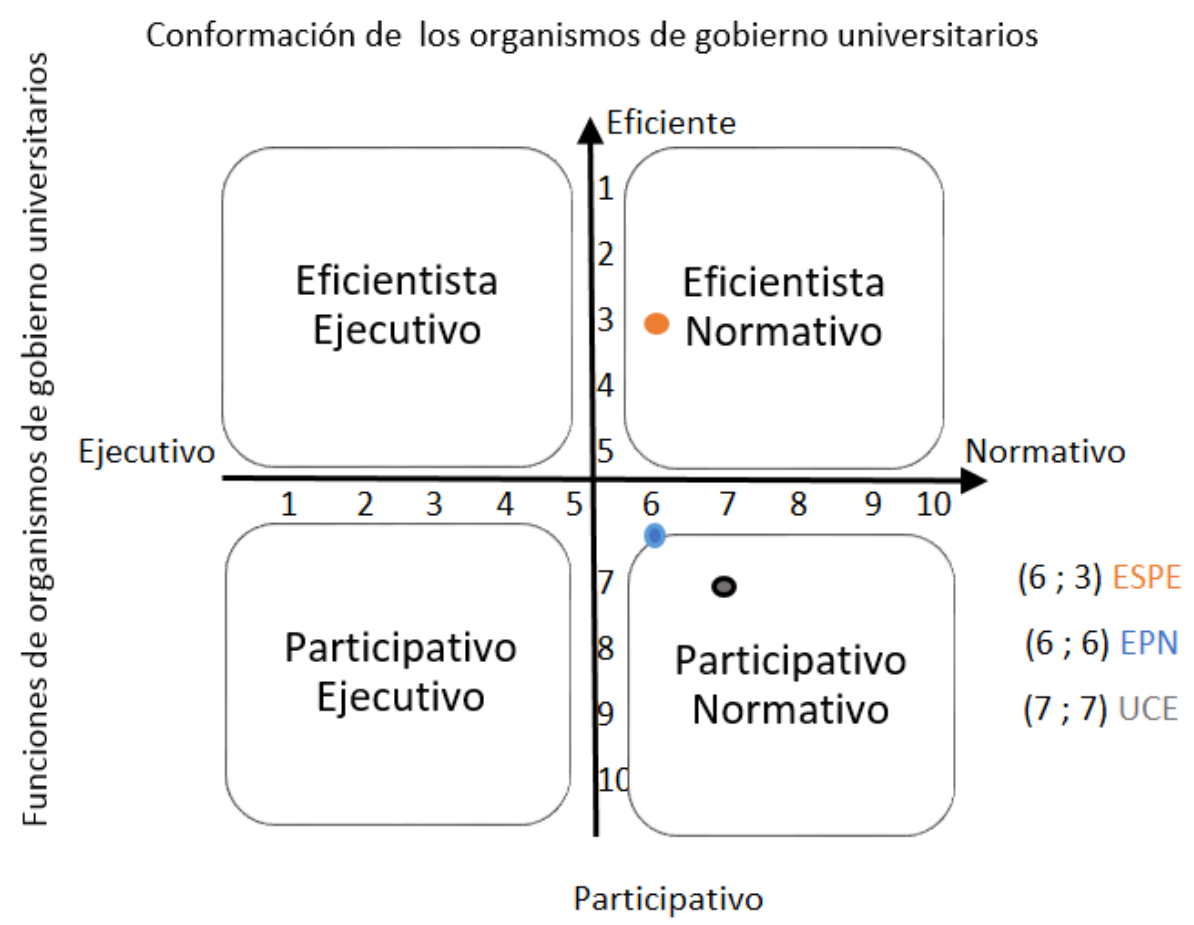

Figura № 2. Modelo de gobernanza universitaria

Fuente: Elaboración Propia

\section{CONCLUSIÓN}

Aun cuando las tres IES que intervienen en el estudio son públicas y domiciliadas en la misma provincia, difieren en la manera con la que se ejercen los cuatro principios de gobernanza, autonomía, libertad académica, rendición de cuentas, participación y representatividad institucional. Esta intensidad determina distintas formas de organización y modelos de operación interna.

Así también la caracterización de las universidades que participan en el estudio respecto a los distintos tipos de gobernanza universitaria, se realiza a partir de las funciones que ejercen los organismos que están en la cúspide de la estructura universitaria (estructura central) y de la forma como se relacionan con los que están jerárquicamente debajo (estructura local).

De aquí se concluye que el modelo de gobernanza de EPN y UCE es predominantemente normativo participativo en su nivel de estructura central, en la medida se observa una conformación de los organismos de gobierno participativo con funciones primordialmente normativas. En su nivel de estructura local predomina el eficientista normativo, toda vez que la conformación de los organismos de gobierno locales es eficientista con funciones primordialmente normativas.

\footnotetext{
"Visión de Futuro" Año 16, Volumen N²3 N², Julio - Diciembre 2019 - Pág. 102 - 121

URL de la Revista: http://visiondefuturo.fce.unam.edu.ar/index.php/visiondefuturo/index

URL del Documento: http://visiondefuturo.fce.unam.edu.ar/index.php/visiondefuturo/issue/view/16

ISSN 1668 - 8708 - Versión en Línea

E-mail: revistacientifica@fce.unam.edu.ar
} 
El modelo de gobernanza de ESPE es predominantemente eficientista normativo en su nivel de estructura central, en la medida se observa una conformación de los organismos de gobierno eficientista con funciones primordialmente normativas. En su nivel de estructura local predomina eficientista ejecutivo, toda vez que se observa una conformación de los organismos de gobierno locales eficientista con funciones primordialmente ejecutivas.

El desarrollo del tema es de interés nacional por lo que existió la apertura necesaria, pese a esto el estudio se circunscribió únicamente a la población de universidades públicas ubicadas en la Provincia de Pichincha, que albergan la mayor parte de la población estudiantil. Sin embargo, en una segunda fase se ampliará la cobertura de estudio en otras provincias del país y hacia IES autofinanciadas y cofinanciadas.

Es importante reconocer que a partir del 2008, el SES ecuatoriano ha estado inmerso en un proceso de transformación hacia una mejora sustancial de la calidad educativa, por lo que es importante complementar el presente estudio para identificar el modelo de gobernanza imperante en el SES en su conjunto y su impacto en el comportamiento observado en las IES. A partir de estos resultados procurar ambientes participativos sobre la base del reconocimiento de la capacidad de las universidades para cumplir su misión histórica y para entregar respuestas pertinentes y oportunas a la sociedad.

\section{REFERENCIAS}

Alcántara, A. (2012). Gobernanza, gobierno y gobernabilidad en la educación superior (Primera ed.). (B. Lerner, R. Uvalle, \& R. Moreno, Edits.) Toluca, México: UNAMIIS/LAPAC. Obtenido de https://www.ses.unam.mx/curso2016/pdf/23-sep-Alcantara.pdf Asamblea Constituyente. (2008). Constitución de la República del Ecuador - Asamblea Nacional. Recuperado

de: www.asambleanacional.gov.ec/documentos/constitucion_de_bolsillo.pdf

Asamblea Nacional. Secretaría de Educación Superior, Ciencia, Tecnología e Innovación. Ley Orgánica de Educación Superior. Quito, Ecuador. 6 de Octubre de 2010. Recuperado de: http://www.educacionsuperior.gob.ec/wpcontent/uploads/downloads/2012/07/loes.pdf

Bengoetxea, E. (2012). La reforma de la gobernanza de la educación superior en la práctica.

Puesta en práctica de los objetivos políticos en la gestión universitaria. Revista de Universidad y Sociedad del Conocimiento, 86-98. Recuperado de: http://www.redalyc.org/articulo.oa?id=78023425008

\footnotetext{
"Visión de Futuro" Año 16, Volumen No 23 N², Julio - Diciembre 2019 - Pág. 102 - 121

URL de la Revista: http://visiondefuturo.fce.unam.edu.ar/index.php/visiondefuturo/index

URL del Documento: http://visiondefuturo.fce.unam.edu.ar/index.php/visiondefuturo/issue/view/16 
Brunner, J. (2011). Gobernanza universitaria: tipología, dinámicas y tendencias. Revista de Educación, 137-159. Recuperado de http://www.revistaeducacion.educacion.es/re355/re355_06.pdf

Brunner, J. J. (2012). La idea de universidad en tiempos de masificación. Revista Iberoamericana de Educación Superior, 3(7), 130-143. Recuperado de https://ries.universia.net/article/viewFile/86/144

Brunner, J. J., \& Ganga, F. A. (2016). Dinámicas de transformación en la educación superior latinoamericana: desafios para la gobernanza. Opción, 12-35. Recuperado de: http://www.redalyc.org/articulo.oa?id=31047691002

Carrasco, A. (2017). Los nuevos modelos de gobernanza universitaria. El caso de la Unión Europea como organismo supranacional que configura el sistema universitario español. Journal of Supranational Policies of Education(Extraordinario), 107-122. Recuperado de: doi:https://doi.org/10.15366/jospoe2017.m1

Castro, D., \& Gairín, J. (2013). Retos en la gobernanza de las universidades españolas. Perspectiva Educacional, 52(1), 4-30. Recuperado de: file:///C:/Users/javierb/Downloads/Dialnet-

LaUniversidadempresaEnEICapitalismoCognitivo-4880004.pdf

CEAACES - Consejo de Evaluación, Acreditación y Aseguramiento de la Calidad de la Educación Superior-. (2015). Título del informe. Recuperado de: http://www.ceaaces.gob.ec/sitio/wp-content/uploads/2016/06/Modelo-deevaluacio\%CC\%81n-institucional-2016.pdf

Cifuentes et al, (2016). Asuntos de Gobierno Universitario. Bogota, Colombia. Editorial Pontificia Universidad Javeriana.

CONEA. (2009). Mandato Constituyente No. 14: Evaluación de Desempeño de las Universidades y Escuelas Politécnicas del Ecuador. Recuperado de: http://www.ceaaces.gob.ec/sitio/wp-

content/uploads/2014/02/INFORME_FINAL_UNIVERSIDADES_M141.pdf

Endika, B. (2012). La reforma de la gobernanza de la educación superior en la práctica. RUSC, 9(2), 86 - 99. doi:<http://dx.doi.org/10.7238/rusc.v9i2.1415>

Ganga et al, (2017). Análisis sincrónico de la gobernanza universitaria: una mirada teórica a los años sesenta y setenta. Educ. Pesqui, 553-568. doi:dx.doi.org/10.1590/S15179702201608135289

Marín, V. (2011). La libertad académica de Conrad Russell. Perfiles Educativos, 33(134), 207-212.

Mayntz, R. (2006). Governance en el Estado moderno. Posdata, 103-120.

\footnotetext{
"Visión de Futuro" Año 16, Volumen N²3 N², Julio - Diciembre 2019 - Pág. 102 - 121

URL de la Revista: http://visiondefuturo.fce.unam.edu.ar/index.php/visiondefuturo/index

URL del Documento: http://visiondefuturo.fce.unam.edu.ar/index.php/visiondefuturo/issue/view/16

ISSN 1668 - 8708 - Versión en Línea

E-mail: revistacientifica@fce.unam.edu.ar
} 
Mora, J. G. (2000). El profesorado universitario: Situación en España y tendencias internacionales. Madrid: Cuadernos del Consejo de Universidades. Recuperado de https://books.google.com.ec/books?id=U5p1gdNIJnwC\&pg=PA33\&dq=Profesorado+un iversitario:+situaci\%C3\%B3n+en+espa\%C3\%B1a+y+tendencias+internacionales+/+m ora+2000\&hl=es\&sa=X\&ved=0ahUKEwjT3cygs9zYAhWJ61MKHfLmBfcQ6AEIJTAA\#v $=$ onepage $\& \mathrm{q}=$ Profesorado\%20universitario

Prats, J. (28 de abril de 2016). Asociación Internacional para la Gobernanza, la Ciudadanía y la Empresa. Obtenido de http://www.aigob.org/category/revista-gobernanza-38/

Puga, R. (26 de Enero de 2018). Gobernanza en las IES públicas de Quito. (J. Buenaño, Encuestador)

Ruiz, B. (25 de Enero de 2018). Gobernanza en las IES públicas de Quito. (B. Maldonado, Encuestador)

San Martín, J. (24 de Enero de 2018). Gobernanza en las IES públicas de Quito. (J. Buenaño, Encuestador)

Uauy et al, (2014). Estudio Técnico N²2. Análisis comparado de tipos de gobernanza y rankings internacionales. Universidad de Chile. Chile. Recuperado de: www.uchile.cl/documentos/resumen-estudio-tecnico-n-22_118152_1_5915.pdf

Virgili et al, (2015). Gobernanza universitaria o cogobierno: El caso de la Universidad de Concepción de Chile. Ultima década, 23(42), 187-216. doi:dx.doi.org/10.4067/S071822362015000100009.

\section{RESUMEN BIOGRAFICO}

\section{Betzabé de Rosario Maldonado Mera}

Magíster en Gestión de Organizaciones, Universidad de Valparaíso - Chile. Candidata a Doctora en Ciencias de la Administración de la Universidad Nacional de La Plata - Argentina. Docente Investigadora de la Universidad de las Fuerzas Armadas ESPE. Coordinadora de la Comisión de Autoevaluación del Departamento de Ciencias Económicas, Administrativas y de Comercio.

\section{José Javier Buenaño Cabrera}

MBA especialidad Marketing, Escuela Politécnica del Ejército - Ecuador. Candidato a Doctora en Ciencias de la Administración de la Universidad Nacional de La Plata - Argentina. Docente Investigador de la Universidad de las Fuerzas Armadas ESPE. Departamento de Ciencias Económicas, Administrativas y de Comercio.

\section{Karla Viviana Benavides Espinosa}

MBA especialidad Marketing, Escuela Politécnica del Ejército - Ecuador. Candidata a Doctora en Ciencias de la Administración de la Universidad Nacional de La Plata - Argentina. Docente Investigadora de la Universidad de las Fuerzas Armadas ESPE. Departamento de Ciencias Económicas, Administrativas y de Comercio. Coordinadora de la Maestría en Mercadotecnia.

\footnotetext{
"Visión de Futuro" Año 16, Volumen No 23 N², Julio - Diciembre 2019 - Pág. 102 - 121

URL de la Revista: http://visiondefuturo.fce.unam.edu.ar/index.php/visiondefuturo/index

URL del Documento: http://visiondefuturo.fce.unam.edu.ar/index.php/visiondefuturo/issue/view/16 